\title{
The Effect of Silicon on Osmotic and Drought Stress Tolerance in Wheat Landraces
}

\author{
Sarah J. Thorne ${ }^{1}\left(\mathbb{D}\right.$, Susan E. Hartley ${ }^{2}$ and Frans J. M. Maathuis $1, * \mathbb{D}$ \\ 1 Department of Biology, University of York, York YO10 5DD, UK; st945@york.ac.uk \\ 2 Department of Animal and Plant Sciences, University of Sheffield, Sheffield S10 2TN, UK; \\ s.hartley@sheffield.ac.uk \\ * Correspondence: frans.maathuis@york.ac.uk
}

Citation: Thorne, S.J.; Hartley, S.E.; Maathuis, F.J.M. The Effect of Silicon on Osmotic and Drought Stress Tolerance in Wheat Landraces. Plants 2021, 10, 814. https://doi.org/ $10.3390 /$ plants10040814

Academic Editor: Vadim Volkov

Received: 25 March 2021

Accepted: 19 April 2021

Published: 20 April 2021

Publisher's Note: MDPI stays neutral with regard to jurisdictional claims in published maps and institutional affiliations.

Copyright: (c) 2021 by the authors. Licensee MDPI, Basel, Switzerland. This article is an open access article distributed under the terms and conditions of the Creative Commons Attribution (CC BY) license (https:/ / creativecommons.org/licenses/by/ $4.0 /)$.

\begin{abstract}
Drought stress reduces annual global wheat yields by $20 \%$. Silicon (Si) fertilisation has been proposed to improve plant drought stress tolerance. However, it is currently unknown if and how Si affects different wheat landraces, especially with respect to their innate Si accumulation properties. In this study, significant and consistent differences in Si accumulation between landraces were identified, allowing for the classification of high Si accumulators and low Si accumulators. Landraces from the two accumulation groups were then used to investigate the effect of Si during osmotic and drought stress. Si was found to improve growth marginally in high Si accumulators during osmotic stress. However, no significant effect of Si on growth during drought stress was found. It was further found that osmotic stress decreased Si accumulation for all landraces whereas drought increased it. Overall, these results suggest that the beneficial effect of Si commonly reported in similar studies is not universal and that the application of $\mathrm{Si}$ fertiliser as a solution to agricultural drought stress requires detailed understanding of genotype-specific responses to $\mathrm{Si}$.
\end{abstract}

Keywords: silicon fertiliser; wheat; osmotic stress; drought stress; landraces; genotypic variation

\section{Introduction}

Wheat is the primary source of calories for $30 \%$ of the world population [1], with over 765 million tonnes of wheat produced globally in 2019 [2]. However, drought causes average global yield losses of $\approx 20 \%$ for wheat [3]. Anthropogenic climate change is predicted to induce changes in global precipitation patterns, with droughts likely to become more frequent in some areas, further exacerbating yield losses [4,5]. The impacts of abiotic stresses such as drought may be exacerbated by the focus of crop domestication on optimising yields at the expense of reduced stress tolerance and genetic diversity [6]. Current mitigation strategies include crop irrigation, but this often results in soil salinisation [7], and breeding for increased drought tolerance, particularly by using the genetic diversity of landraces to breed cultivars with improved drought tolerance [8]. However, breeding approaches are slow, labour intensive and complicated by genotype-environment interactions [9].

Silicon (Si) is the second most abundant element in the earth's crust [10]. Although not considered an essential element in plants, Si accumulation has been linked to improved growth, especially in plants under stress [11]. However, plants only absorb $\mathrm{Si}$ as silicic acid, which is often limited in the soil [12]. In grasses, silicic acid is transported through the roots by the action of two transporters: Lsi1 and Lsi2 [13]. While most silicic acid is transported to the shoots, some is deposited in the roots, predominantly in the tangential and radial walls of endo- and exodermal tissues [14,15]. The majority of absorbed Si passes through the transpiration stream to the shoots [16]. In rice, the Si transporters Lsi2, Lsi3 and Lsi6 are involved in unloading silicic acid out from the xylem into the shoot [17]. High levels of silicic acid in the shoot cause its autopolymerisation into silica [18]. Deposited silica can be found in the form of phytoliths, silicified spines and surface structures, which occur in a 
range of shoot tissues $[19,20]$. Silica also accumulates in or beneath the cuticle layer of the cell wall in epidermal cell layers and tissues that surround the vasculature [18,21-23].

Si fertilisation may improve drought tolerance, although the exact underpinning mechanisms are unknown [24]. Drought stress induces oxidative damage [25], and Si fertilisation has been shown to reduce oxidative damage, notably by increasing antioxidative enzyme activity [26-28]. Additionally, Si fertilisation can improve water use efficiency during drought stress [28-30], for example, via an increase in stomatal conductance, which in turn improves the photosynthetic rate [31-33]. In contrast, other studies showed improved water use efficiency linked to lower transpiration, which may occur via reduction in cuticular water conductance [34,35].

Most studies on wheat report that $\mathrm{Si}$ increases growth and yield under drought stress [28,36-38], although there are others reporting no significant effect either in wheat [39] or in other species $[40,41]$. The inconsistent nature of the observed Si effects may reflect variation in plant species and genotype, as has been found for understanding the Si effect on herbivory tolerance [20,42,43]. For example, genotypic variability in $\mathrm{Si}$ accumulation is likely to affect the Si response, and while many studies assessed the effect of Si on cultivars that differ in drought tolerance [44-46], there is a clear lack of studies examining the effect of $\mathrm{Si}$ on drought tolerance in a larger range of genotypes, particularly those that vary in Si accumulation.

Although there is increasing interest in the use of local landraces in crop breeding programs to improve stress tolerance $[8,47]$, to date, only a few studies have used landraces to investigate the effect of $\mathrm{Si}$ on osmotic and drought stress in wheat $[48,49]$. In this study, whether there are consistent differences in Si accumulation between wheat landraces was assessed. Whether there is a different effect of Si on osmotic and drought stress in landraces with relatively high Si content compared to those with lower Si content was then examined. It was hypothesised that the impact of Si on stress tolerance in landraces depends on their capacity to accumulate $\mathrm{Si}$.

\section{Materials and Methods}

\subsection{Plant Material, Experimental Design and Growth Conditions \\ 2.1.1. Wheat Diversity Panel}

A diversity panel of 98 Triticum aestivum landraces, which is part of the 350 landraces YoGI biodiversity panel (Harper, unpublished data), was used. The panel was formed using material from the following collections: The International Maize and Wheat Improvement Center (CIMMYT), Mexico; Crop Research Institute, Prague; and John Innes Germplasm Resource Unit, the Biotechnology and Biological Sciences Research Council Designing Future Wheat programme. A full list of landraces is available in Table S1 in the Supplementary Materials.

\subsubsection{Growth of Wheat in Compost}

Seeds for each T. aestivum landrace were planted in $500 \mathrm{~mL}$ pots filled with F2 + S compost (Levington) and placed in controlled glasshouse $\left(15-20^{\circ} \mathrm{C}, 16: 8 \mathrm{hr}\right.$ light:dark). Prior to seed planting, pots filled with compost were treated with Calypso insecticide (Bayer) according to the manufacturer's instructions. One week after germination, the seedlings were thinned to 2 plants per pot. The plants were grown in the glasshouse for 7 weeks and watered as required with tap water. The plants were cultivated with or without Si fertilisation. For plants grown with $\mathrm{Si}$, the plants received $100 \mathrm{~mL} 1.5 \mathrm{mM}$ sodium metasilicate (Sigma-Aldrich, St. Louis, MO, USA) twice weekly, starting one week after germination and continuing for 42 days when the shoots were sampled. All experiments consisted of four temporally separate replicates, with at least two weeks between experiments, apart from the screen using the diversity panel, which consisted of three replicates. Each replicate consisted of one plant per landrace per treatment. At harvest, the shoot fresh weight was recorded, the plants were oven-dried at $70{ }^{\circ} \mathrm{C}$ for $72 \mathrm{~h}$ to obtain shoot dry weights, and shoot $\mathrm{Si}$ concentration was measured as described below. 


\subsubsection{Growth of Wheat in Hydroponics}

The seeds of landraces were germinated in the glasshouse in sand for 10-11 days, and then, the seedlings were transferred to $9 \mathrm{~L}$ hydroponics boxes, filled with $1 / 2$ strength Hoagland's solution supplemented with $\mathrm{Si}$ as indicated. The $\mathrm{pH}$ was adjusted to 5.6-6.0 using $1 \mathrm{M} \mathrm{HCl}$ or $0.1 \mathrm{M} \mathrm{KOH}$. For Si fertilisation, sodium metasilicate (Sigma-Aldrich, St. Louis, MO, USA) was added to achieve final Si concentrations of $0.2,0.9$ or $1.8 \mathrm{mM}$. Across all levels of $\mathrm{Si}$ availability, sodium chloride was used to balance sodium levels. The nutrient solution was changed every $3-4$ days. The hydroponics boxes were aerated throughout the experiment. The plants were grown under controlled glasshouse conditions $\left(15-20{ }^{\circ} \mathrm{C}, 16: 8 \mathrm{hr}\right.$ light:dark) and sampled 6 weeks after germination. At the end of the experiment, the roots were washed in deionised water and the shoot and root fresh weights were recorded. The plants were oven-dried at $70^{\circ} \mathrm{C}$ for $72 \mathrm{~h}$ to obtain dry weights. The shoot and root $\mathrm{Si}$ concentrations were measured as described below.

\subsubsection{Imposition of Stress Conditions}

To impose osmotic stress, the hydroponically grown plants were exposed to $8 \%(w / v)$ polyethylene glycol-(PEG)6000 (Sigma-Aldrich, St. Louis, MO, USA), which was calculated to have an osmotic pressure of $-0.12 \mathrm{MPa}$ [50]. The plants were treated for 4 weeks, and the experiment was composed of four replicates, with a minimum of two weeks between replicates.

Drought stress was applied to the soil-grown plants by withholding watering until $40 \%$ field capacity (FC) was achieved. All plants were then watered as required to maintain the soil moisture at either control (100\% FC) or drought ( $40 \%$ FC) levels. The soil moisture content was checked using a soil moisture probe (ML3 ThetaProbe Soil Moisture Sensor, delta-T). The plants were harvested 6 weeks after sowing. Four replicates were performed, with a minimum of two weeks between replicates and two plants per landrace per treatment per replicate.

\subsection{Silicon Measurements}

Shoot and root $\mathrm{Si}$ concentrations were measured by portable X-ray fluorescence spectroscopy (P-XRF) using the method described in Reidinger et al. [51]. The dried leaf material was ball-milled (Retsch MM400 Mixer mill, Haan, Germany), and the ground material was pressed at 10 tons into pellets using a manual hydraulic press with a $13 \mathrm{~mm}$ die (Specac, Orpington, UK). Si analysis (\% Si dry weight) was performed using a commercial P-XRF instrument (Nitron XL3t900 GOLDD analyser: Thermo Scientific Winchester, UK) held in a test stand (SmartStand, Thermo Scientific, Winchester, UK). The P-XRF machine was calibrated using Si-spiked synthetic methyl cellulose (Sigma-Aldrich, product no. 274429) and validated using Certified Reference Materials of NCS DC73349 'Bush branches and leaves' obtained from the China National Analysis Center for Iron and Steel. To avoid signal loss by air absorption, the analyses were performed under a helium atmosphere [50]. A reading of each side of the pellet was taken approximately one hour apart to account for $\mathrm{u}$-drift in the instrument (i.e., variation in readings between consecutive runs using identical parameters [52]). The two readings were averaged to estimate the Si concentration (\%).

\subsection{Statistical Analysis}

All statistical analyses were performed using R software [53] (version 3.6.1). Threeway analysis of variance (ANOVA) was used to test the effect of Si fertilisation, stress treatment, and landrace or accumulation type on Si concentration, dry weight and stress tolerance. Stress tolerance in non-fertilised and $\mathrm{Si}$ fertilised conditions was calculated as the ratio of growth of stressed plants compared to control plants (Stress/Control and Stress $+\mathrm{Si} /$ Control $+\mathrm{Si}$, respectively). In all ANOVAs, temporal replicate was included as a factor to account for variation caused by plants that were grown at different times. Data normality was checked using Shapiro tests, and homogeneity of variance was tested using Levene's tests. Dry weights and stress tolerance were log transformed, and Si concentration was 
logit transformed to satisfy the test assumptions. Post hoc Tukey's HSD tests were used when significant interaction terms were present.

\section{Results}

\subsection{Variation in Si Concentration in a Wheat Diversity Panel and Selection of High and Low Accumulators}

The 98 landraces were grown in compost and ranked according to their shoot $\mathrm{Si}$ levels for both the non-fertilised and Si fertilised conditions. The 10 highest and 10 lowest scoring landraces were then cultivated in hydroponics to control the Si supply more accurately and to assess whether ranking was consistent across growing systems and the amount of $\mathrm{Si}$ supplied to the growth medium. These combined analyses allowed for identification of five landraces that consistently showed relatively high and five landraces that consistently showed relatively low shoot $\mathrm{Si}$ accumulation for compost grown plants (Figure 1a) and hydroponically grown plants (Figure 1b). Furthermore, the plants from hydroponics showed that the shoot accumulation pattern was reproduced in root tissue (Figure 1b). Based on these data, a 'high' or 'low' Si accumulation type was assigned to each of the 10 landraces.
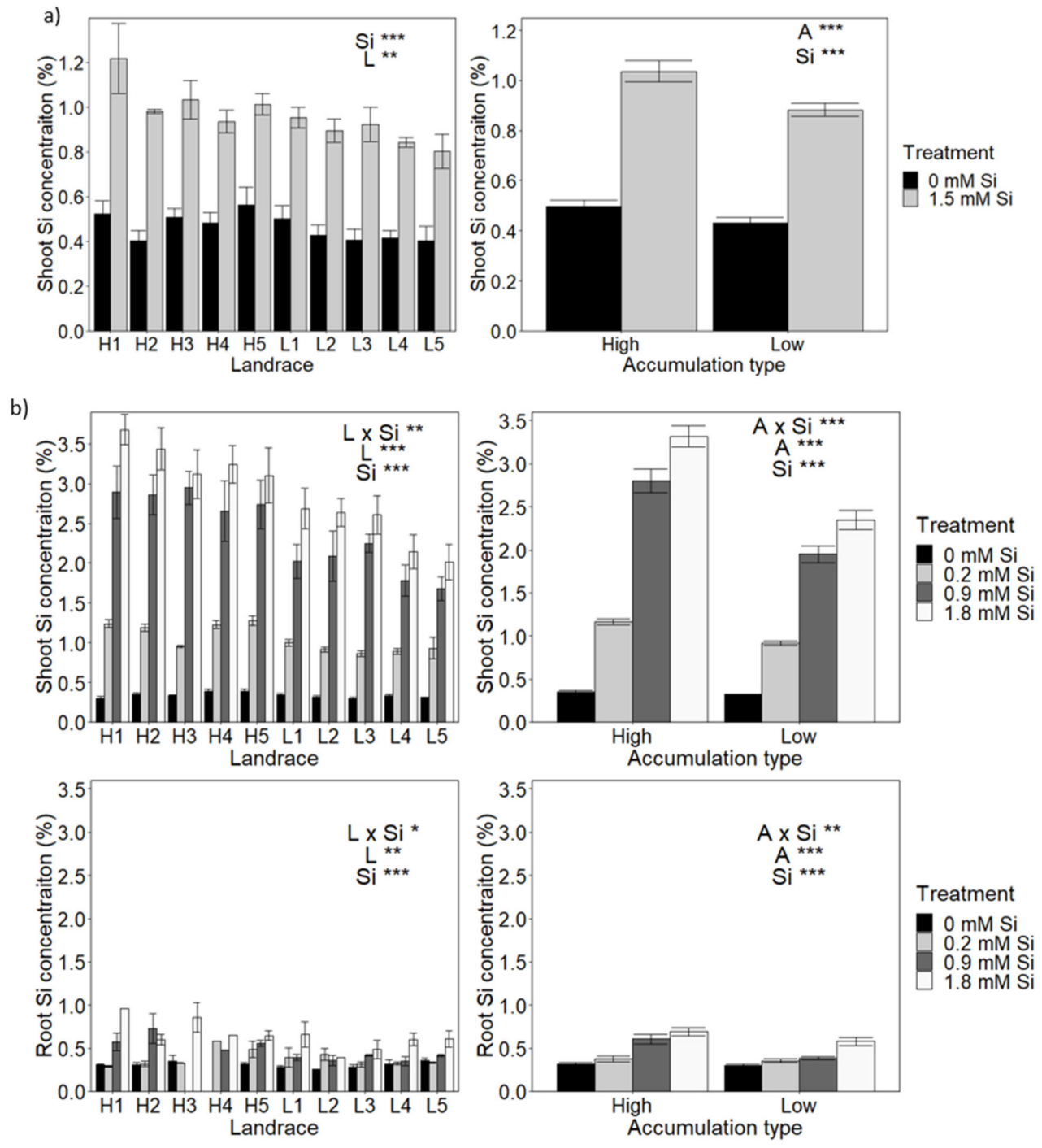

Figure 1. Variation in Si accumulation among selected wheat landraces. Ten wheat landraces were grown in (a) compost or (b) hydroponically with varying levels of Si fertilisation. Si level was measured for each landrace (left-hand panels). Average Si values, after classification into high and low Si accumulators, are shown in the right-hand panels. Statistically significant impacts and interactions, determined by 3-way ANOVA, are indicated in each panel, where ${ }^{* * *} p<0.001,{ }^{* *} p<0.01$ and ${ }^{*} p<0.05$. Mean values $\pm \mathrm{SE}$ are shown. $\mathrm{N}=3$. L: Landrace, A: accumulation type, Si: level of Si fertilisation. 
When cultivated in compost, shoot Si concentration in the selected 10 landraces was significantly affected by both landrace and Si fertilisation, but no interaction was found between these variables (Figure 1a; Table S2 in the Supplementary Materials). When grown with $\mathrm{Si}$, the average Si concentration for the five high Si landraces was $1.04 \%$ compared to $0.88 \%$ for the five low Si landraces, a small but significant difference between accumulation types (Figure 1a; Table S2).

For hydroponically grown plants, Si fertilisation, landrace and the interaction between these factors, all had significant effects on shoot as well as root Si concentrations (Figure 1b; Table S2). The same pattern of significant effects on shoot and root Si contents were found for accumulation type (Figure 1b; Table S2). Thus, high accumulators not only accumulate more $\mathrm{Si}$ but also are more responsive to Si addition. For example, high accumulators showed bigger increases in Si uptake in response to $0.9 \mathrm{mM}$ Si than low accumulators (Figure 1b). Shoot Si concentrations were higher in hydroponic-grown plants than in compost-grown ones, and the difference between high and low accumulators was greater, with an average of $3.24 \%$ Si for high accumulators grown in $1.8 \mathrm{mM}$ Si compared to $2.35 \%$ Si for low accumulators.

\subsection{The Effect of Accumulation Type and Si Supply on Plant Growth during Osmotic Stress}

Osmotic stress, Si fertilisation and accumulation type significantly affected shoot dry weight (Table S3). Si improved shoot biomass when plants were exposed to PEG for the high accumulation type only, and the effect of Si fertilisation was relatively small (Figure 2a).
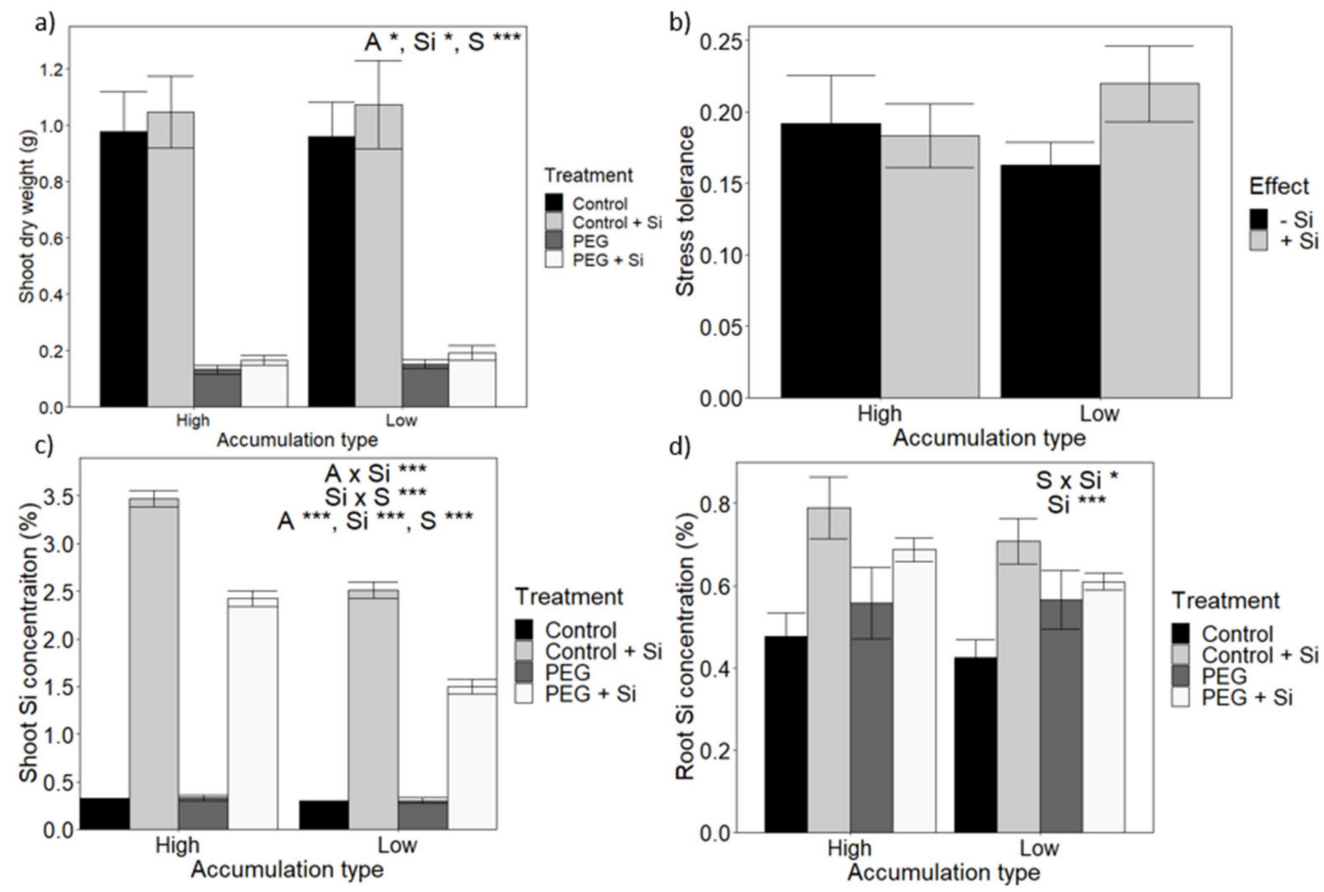

Figure 2. The impact of Si fertilisation on wheat osmotic stress tolerance according to Si accumulation type. (a) Shoot dry weight (DW). (b) Growth data were normalised to express 'Stress tolerance', defined as the ratio between shoot growth under osmotic stress compared to the control. (c) Shoot Si concentration. (d) Root Si concentration. Statistically significant impacts and interactions, determined by 3-way ANOVA, are indicated in each panel, where ${ }^{* * *} p<0.001,{ }^{* *} p<0.01$ and ${ }^{*} p<0.05$. Mean values $\pm \mathrm{SE}$ are shown. $\mathrm{N}=4$. L: Landrace, A: accumulation type, Si: level of Si fertilisation, S: osmotic stress treatment.

To facilitate comparisons between high and low Si accumulators, growth data were normalised and expressed as 'Stress tolerance', defined as the ratio of growth during stress compared to growth in the control. The stress tolerance was calculated separately for 
$-\mathrm{Si}$ and $+\mathrm{Si}$ plants. Neither Si fertilisation nor Si accumulation type significantly affected osmotic stress tolerance (Figure $2 b$ ).

As can be seen in Figure 2c,d, during osmotic stress, the high and low Si accumulation traits were preserved, with significantly higher shoot and root $\mathrm{Si}$ levels for the high $\mathrm{Si}$ accumulators. Interestingly, for plants that were Si fertilised, an imposition of osmotic stress itself led to a large reduction in shoot, but not root, Si concentration relative to the results for the non-stressed plants.

Overall, no impact of Si on stress tolerance was observed in either the high or low $\mathrm{Si}$ accumulators. This lack of response may be due to the fact that $\mathrm{Si}$ impact is insignificant in all of the lines or because the positive Si effect of one line is cancelled by the negative response of another. However, Figure S1 shows that, across all the landraces, there was no significant effect of $\mathrm{Si}$ on stress tolerance in any of the landraces, ruling out the latter explanation.

\subsection{The Effect of Accumulation Type and Si Supply on Growth during Drought Stress}

Osmotic stress applied using chemical agents such as PEG is frequently applied to plants to mimic physiological drought. Such hydroponics-based assays have the advantage of exposing plants to a better controlled and less complex growth substrate and allows access to roots. However, genuine drought stress, i.e., water deficit, better simulates real field conditions. Furthermore, responses to osmotic and drought stress can be very different $[54,55]$. This study was therefore repeated using compost-grown wheat where water deficits could be applied.

Drought stress (i.e., 40\% FC) significantly the lowered shoot dry weight by around 50\% (Figure 3a). This reduction in biomass was the same for both high and low $\mathrm{Si}$ accumulators, and the addition of Si did not significantly alter the observed pattern (Table S4).

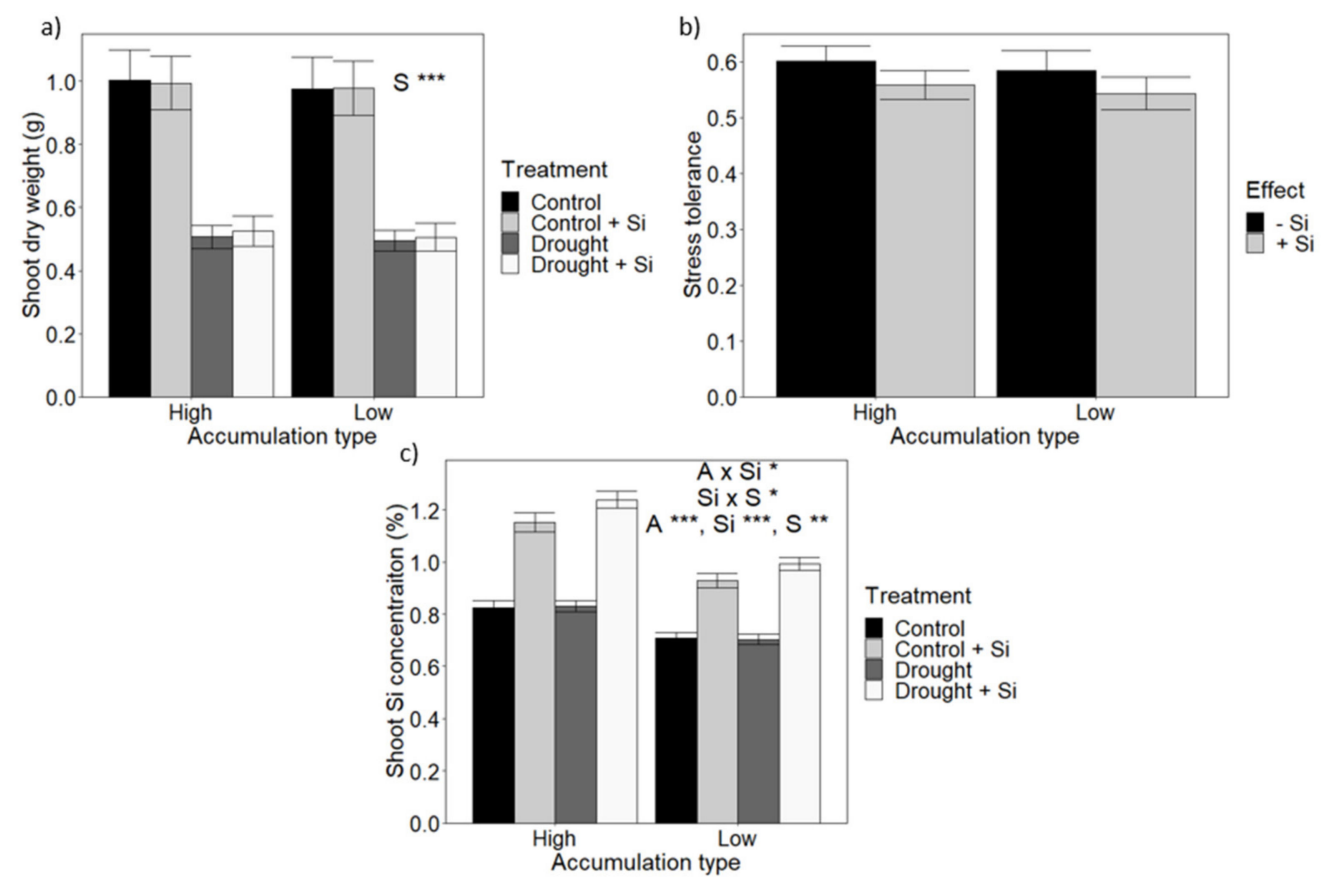

Figure 3. The impact of Si fertilisation on wheat drought stress tolerance. (a) Shoot dry weight (DW). (b) Growth data were normalised to express 'Stress tolerance', defined as the ratio between shoot growth under drought stress compared to the control. (c) Shoot Si concentration. Statistically significant impacts and interactions, determined by 3-way ANOVA, are indicated in each panel, where ${ }^{* * *} p<0.001,{ }^{* *} p<0.01$ and ${ }^{*} p<0.05$. Mean values $\pm \mathrm{SE}$ are shown. $\mathrm{N}=20$. L: Landrace, A: accumulation type, $\mathrm{Si}$ : level of Si fertilisation, S: drought stress treatment. 
In addition to the effect of $\mathrm{Si}$ on absolute growth, the $\mathrm{Si}$ effect on stress tolerance was investigated. Stress tolerance (Figure $3 b$ ) was the same in high and low $\mathrm{Si}$ accumulators; $\mathrm{Si}$ fertilisation did not have a significant effect on tolerance to drought stress.

Figure $3 c$ shows that, for compost-grown plants in all four $\mathrm{Si} \times$ drought treatments, the high accumulators had higher levels of shoot $\mathrm{Si}$ than the low accumulators. Furthermore and in contrast to the findings here for osmotic stress, when water availability was lowered, it caused an increase in shoot $\mathrm{Si}$ levels of Si fertilised plants (Figure 3c). This increase was larger for the high $\mathrm{Si}$ accumulators compared to the low $\mathrm{Si}$ accumulators.

As with osmotic stress, the effect of $\mathrm{Si}$ on stress tolerance on each landrace was investigated to verify that the lack of $\mathrm{Si}$ response was not the result of positive effects in some landraces being cancelled by negative effects in other landraces. There was no significant effect of Si on stress tolerance for any individual landrace (Figure S2).

\section{Discussion}

Si fertilisation could be a cost-effective method to mitigate water stress in crops. However, reports on its efficacy vary widely and uncertainty regarding the underpinning mechanisms remain. An important question in this regard is whether and how variation in plant $\mathrm{Si}$ accumulation relates to $\mathrm{Si}$ impact on plant growth during water stress. Previous studies have investigated the differences in $\mathrm{Si}$ accumulation between genotypes $[20,56,57]$ and the effect of Si accumulation on growth, including yield. For example, Merah et al. [48] found no significant correlation between Si content and grain yield among 10 durum wheat genotypes. However, to our knowledge, no studies have correlated the differences in $\mathrm{Si}$ accumulation with differences in stress tolerance. To address this question, whether there is a different effect of $\mathrm{Si}$ on osmotic and drought stress in landraces with high $\mathrm{Si}$ content compared to those with low Si content was examined.

In spite of the significant differences in both shoot and root $\mathrm{Si}$ contents between the low and high accumulator groups (Figure 1) and with the exception of a small growth improvement for PEG-treated high accumulators (Figure 2), no difference in growth or stress tolerance was observed between accumulator types irrespective of treatment (Figures 2 and 3). A similar conclusion is arrived at when investigating Si impact on individual landraces. Thus, these findings do not corroborate wheat studies that found that $\mathrm{Si}$ improves growth under osmotic [58] and drought stress [28,36-38]. Nevertheless, other studies on osmotic and drought-stressed wheat did not report a significant increase in shoot dry weight biomass [39,59]. Furthermore, a lack of response to Si has also been reported for many other crop species. For example, Ruppenthal et al. [60] reported that Si did not improve growth during drought in soybean, although $\mathrm{Si}$ did reduce membrane damage and increased peroxidase activity. In the case of barley, osmotic stress led to a rise in tissue Si but it did not alter biomass [40,41], and a similar result was reported in tall fescue [34].

These disparities may be (partly) due to methodological aspects; for instance, many studies used Na or K silicate as the Si treatment but failed to correct for cation concentrations in the control treatment. Hence, it is likely that the observed Si response is in fact due to extra $\mathrm{Na}$ or $\mathrm{K}$ fertilisation. Interpretational divergence is another potential source of confusion; many studies report a positive impact of Si on tolerance to osmotic or drought stress, when in reality, the effects of $\mathrm{Si}$ are already obvious in control treatments and hence are not stress specific.

Genotype-specific Si responses could be another important factor; Hu et al. [61] found that the positive effect of $\mathrm{Si}$ on growth in poinsettia under control conditions was cultivar dependent. In sugarcane, the effect of Si under water-deficit conditions varied among cultivars, with a significant positive effect on dry weight observed in only one out of four tested cultivars [62]. Similar, genotype-specific effects of Si under drought stress have also been found when investigating 12 sunflower cultivars [63]. In wheat, Sapre and Vakharia [64] found variation both in the physiological response to osmotic stress and in $\mathrm{Si}$ accumulation among 10 wheat cultivars. 
Clearly, there is great, genotype-dependent variability in the Si effects, and this could go some way in explaining the lack of responses to Si within an accumulation type if positive and negative changes in stress tolerance for individual landraces tend to cancel each other. This possibility was tested by examining the responses of individual landraces to Si: the impact of Si fertilisation on stress tolerance did vary between landraces from around 25 to $+40 \%$ during osmotic stress (Figure S1) and from around -30 to $+10 \%$ during drought (Figure S2), but none of these changes was significant.

Since Si fertilization did not change the stress tolerance, the hypothesis that Si correlates with tissue Si contents could not be properly tested. However, interesting interactions between stress and tissue Si content were found; during osmotic stress, the levels of Si in shoots were greatly reduced, whereas after exposure to drought, the opposite was observed, i.e., Si content increased. These effects were observed consistently across most landraces. Decreased Si accumulation in response to osmotic stress imposed using PEG has been previously reported $[41,60,61,65]$. Additionally, studies in both wheat $[28,66]$ and other species have reported decreased Si accumulation during drought stress $[29,67,68]$. Nevertheless, increased Si during drought, as found in this study, has also been reported in the literature [30,69]. It is not clear what, if any, the physiological relevance is of these processes and whether they are part of a mechanistic link between Si accumulation and stress response. The similarity in physiological responses to osmotic and drought stress would, perhaps naively, suggest parallel changes in the accumulation of Si in response to both conditions, though they may be species dependent.

\section{Conclusions}

In this study, it was shown that wheat landraces varied significantly and consistently in their Si accumulation, such that two groups, high Si accumulators and low Si accumulators, could be identified. Osmotic stress decreased the Si content in both accumulation types whereas drought increased it. However, no significant effect of Si on growth during drought stress was found, and Si was found to improve growth only slightly in high Si accumulators during osmotic stress. The failure reported here to observe clear positive effects of Si suggest that, for wheat, any mitigation of the impacts of water stress by Si is limited. Further research is required to establish whether modern cultivars exhibit a more positive response toward Si fertilization compared to the landraces used in this study.

Supplementary Materials: The following are available online at https: / www.mdpi.com/article / 10.3390/plants10040814/s1, Figure S1: The impact of Si fertilisation on individual wheat landraces under osmotic stress, Figure S2: The impact of Si fertilisation on individual wheat landraces under drought stress, Table S1: Shoot Si concentrations for the 98 landrace diversity panel, Table S2: ANOVA for the effect of Si fertilisation, for landrace or Si accumulation type, and for their interactions on the tissue Si contents of plants grown in compost or hydroponics, Table S3: ANOVA for osmotic stress, Si fertilisation and Si accumulation type and for their interactions on shoot dry weight, Si concentration and stress tolerance in hydroponic-grown plants, Table S4: ANOVA for osmotic stress, Si fertilisation and $\mathrm{Si}$ accumulation type and for their interactions on shoot dry weight, Si concentration and stress tolerance in compost-grown plants.

Author Contributions: Conceptualization, S.J.T., S.E.H. and F.J.M.M.; methodology, S.J.T., S.E.H. and F.J.M.M.; formal analysis, S.J.T.; investigation, S.J.T.; data curation, S.J.T.; writing-original draft preparation, S.J.T.; writing - review and editing, S.E.H. and F.J.M.M.; funding acquisition, S.E.H. and F.J.M.M. All authors have read and agreed to the published version of the manuscript.

Funding: This work was supported by the Biotechnology and Biological Sciences Research Council (Award ref 1949569).

Data Availability Statement: Not applicable.

Acknowledgments: The authors thank the Biotechnology and Biological Sciences Research Council for funding of the project. We are grateful to Andrea Harper for providing the seeds for this project. 
Conflicts of Interest: The authors declare no conflict of interest. The funders had no role in the design of the study; in the collection, analyses or interpretation of data; in the writing of the manuscript; or in the decision to publish the results.

\section{References}

1. Chaves, M.S.; Martinelli, J.A.; Wesp-Guterres, C.; Graichen, F.A.S.; Brammer, S.P.; Scagliusi, S.M.; da Silva, P.R.; Wiethölter, P.; Torres, G.A.M.; Lau, E.Y.; et al. The importance for food security of maintaining rust resistance in wheat. Food Secur. 2013, 5 , 157-176. [CrossRef]

2. FAOSTAT. Available online: http:/ / www.fao.org/faostat/en/\#data/QC/visualize (accessed on 1 September 2020).

3. Daryanto, S.; Wang, L.; Jacinthe, P.A. Global synthesis of drought effects on maize and wheat production. PLoS ONE 2016, 11, e0156362. [CrossRef]

4. IPCC. Climate Change 2014: Synthesis Report. Contribution of Working Groups I, II, and III to the Fifth Assessment Report of The Intergovernmental Panel on Climate Change; Pachauri, R.K., Meyer, L.A., Eds.; IPCC: Geneva, Switzerland, 2014 ; ISBN 9789291691432.

5. IPCC. Climate Change and Land: An IPCC Special Report on Climate Change, Desertification, Land Degradation, Sustainable Land Management, Food Security, and Greenhouse Gas Fluxes in Terrestrial Ecosystems; Shukla, P.R., Skea, J., Calvo Buendia, E., MassonDelmotte, V., Pörtner, H.-O., Roberts, D.C., Zhai, P., Slade, R., Connors, S., van Diemen, R., et al., Eds.; IPCC: Geneva, Switzerland, 2019.

6. Kahiluoto, H.; Kaseva, J.; Balek, J.; Olesen, J.E.; Ruiz-Ramos, M.; Gobin, A.; Kersebaum, K.C.; Takáč, J.; Ruget, F.; Ferrise, R.; et al. Decline in climate resilience of european wheat. Proc. Natl. Acad. Sci. USA 2019, 116, 123-128. [CrossRef] [PubMed]

7. Martínez-Alvarez, V.; Martin-Gorriz, B.; Soto-García, M. Seawater desalination for crop irrigation-A review of current experiences and revealed key issues. Desalination 2016, 381, 58-70. [CrossRef]

8. Dwivedi, S.L.; Ceccarelli, S.; Blair, M.W.; Upadhyaya, H.D.; Are, A.K.; Ortiz, R. Landrace Germplasm for Improving Yield and Abiotic Stress Adaptation. Trends Plant Sci. 2016, 21, 31-42. [CrossRef]

9. Bhat, J.A.; Deshmukh, R.; Zhao, T.; Patil, G.; Deokar, A.; Shinde, S.; Chaudhary, J. Harnessing High-throughput Phenotyping and Genotyping for Enhanced Drought Tolerance in Crop Plants. J. Biotechnol. 2020, 324, 248-260. [CrossRef] [PubMed]

10. Epstein, E. The anomaly of silicon in plant biology. Proc. Natl. Acad. Sci. USA 1994, 91, 11-17. [CrossRef]

11. Debona, D.; Rodrigues, F.A.; Datnoff, L.E. Silicon's Role in Abiotic and Biotic Plant Stresses. Annu. Rev. Phytopathol. 2017, 55, 85-107. [CrossRef]

12. Côté-Beaulieu, C.; Chain, F.; Menzies, J.G.; Kinrade, S.D.; Bélanger, R.R. Absorption of aqueous inorganic and organic silicon compounds by wheat and their effect on growth and powdery mildew control. Environ. Exp. Bot. 2009, 65, 155-161. [CrossRef]

13. Ma, J.F.; Yamaji, N. A cooperative system of silicon transport in plants. Trends Plant Sci. 2015, 20, 435-442. [CrossRef]

14. Bennett, D.M. Silicon deposition in the roots of Hordeum sativum Jess, Avena sativa L. and Triticum aestivum L. Ann. Bot. 1982, 50, 239-245. [CrossRef]

15. Lux, A.; Luxová, M.; Abe, J.; Tanimoto, E.; Hattori, T.; Inanaga, S. The dynamics of silicon deposition in the sorghum root endodermis. New Phytol. 2003, 158, 437-441. [CrossRef]

16. Yoshida, S.; Ohnishi, Y.; Kitagishi, K. Histochemistry of Silicon in Rice Plant. Soil Sci. Plant Nutr. 1962, 8, 1-5. [CrossRef]

17. Yamaji, N.; Sakurai, G.; Mitani-Ueno, N.; Ma, J.F. Orchestration of three transporters and distinct vascular structures in node for intervascular transfer of silicon in rice. Proc. Natl. Acad. Sci. USA 2015, 112, 11401-11406. [CrossRef]

18. Yoshida, S.; Ohnishi, Y.; Kitagishi, K. Chemical forms, mobility and deposition of silicon in rice plant. Soil Sci. Plant Nutr. 1962, 8 , 15-21. [CrossRef]

19. Shakoor, S.A.; Bhat, M.A.; Mir, S.H. Phytoliths in Plants: A Review. J. Bot. Sci. 2014, 3, 10-24.

20. Hartley, S.E.; Fitt, R.N.; McLarnon, E.L.; Wade, R.N. Defending the leaf surface: Intra- and inter-specific differences in silicon deposition in grasses in response to damage and silicon supply. Front. Plant Sci. 2015, 6, 35. [CrossRef]

21. Sakai, W.; Thom, M. Localization of silicon in specific cell wall layers of the stomatal apparatus of sugar cane by use of energy dispersive X-ray analysis. Ann. Bot. 1979, 44, 245-248. [CrossRef]

22. Peleg, Z.; Saranga, Y.; Fahima, T.; Aharoni, A.; Elbaum, R. Genetic control over silica deposition in wheat awns. Physiol. Plant. 2010, 140, 10-20. [CrossRef] [PubMed]

23. Kumar, S.; Milstein, Y.; Brami, Y.; Elbaum, M.; Elbaum, R. Mechanism of silica deposition in sorghum silica cells. New Phytol. 2017, 213, 791-798. [CrossRef] [PubMed]

24. Thorne, S.J.; Hartley, S.E.; Maathuis, F.J.M. Is Silicon a Panacea for Alleviating Drought and Salt Stress in Crops? Front. Plant Sci. 2020, 11, 1221. [CrossRef]

25. Osakabe, Y.; Osakabe, K.; Shinozaki, K.; Tran, L.-S.P. Response of plants to water stress. Front. Plant Sci. 2014, 5, 86. [CrossRef]

26. Gong, H.; Zhu, X.; Chen, K.; Wang, S.; Zhang, C. Silicon alleviates oxidative damage of wheat plants in pots under drought. Plant Sci. 2005, 169, 313-321. [CrossRef]

27. Tale Ahmad, S.; Haddad, R. Study of silicon effects on antioxidant enzyme activities and osmotic adjustment of wheat under drought stress. Czech J. Genet. Plant Breed. 2011, 47, 17-27. [CrossRef]

28. Alzahrani, Y.; Kuşvuran, A.; Alharby, H.F.; Kuşvuran, S.; Rady, M.M. The defensive role of silicon in wheat against stress conditions induced by drought, salinity or cadmium. Ecotoxicol. Environ. Saf. 2018, 154, 187-196. [CrossRef] 
29. Ibrahim, M.A.; Merwad, A.R.M.; Elnaka, E.A. Rice (Oryza Sativa L.) Tolerance to Drought Can Be Improved by Silicon Application. Commun. Soil Sci. Plant Anal. 2018, 49, 945-957. [CrossRef]

30. Merwad, A.R.M.A.; Desoky, E.S.M.; Rady, M.M. Response of water deficit-stressed Vigna unguiculata performances to silicon, proline or methionine foliar application. Sci. Hortic. 2018, 228, 132-144. [CrossRef]

31. Sonobe, K.; Hattori, T.; An, P.; Tsuji, W.; Eneji, E.; Tanaka, K.; Inanaga, S. Diurnal variations in photosynthesis, stomatal conductance and leaf water relation in sorghum grown with or without silicon under water stress. J. Plant Nutr. 2009, 32, 433-442. [CrossRef]

32. Yin, L.; Wang, S.; Liu, P.; Wang, W.; Cao, D.; Deng, X.; Zhang, S. Silicon-mediated changes in polyamine and 1-aminocyclopropane1-carboxylic acid are involved in silicon-induced drought resistance in Sorghum bicolor L. Plant Physiol. Biochem. 2014, 80, $268-277$. [CrossRef]

33. Wang, Y.; Zhang, B.; Jiang, D.; Chen, G. Silicon improves photosynthetic performance by optimizing thylakoid membrane protein components in rice under drought stress. Environ. Exp. Bot. 2019, 158, 117-124. [CrossRef]

34. Vandegeer, R.K.; Zhao, C.; Cibils-Stewart, X.; Wuhrer, R.; Hall, C.R.; Hartley, S.E.; Tissue, D.T.; Johnson, S.N. Silicon deposition on guard cells increases stomatal sensitivity as mediated by $\mathrm{K}^{+}$efflux and consequently reduces stomatal conductance. Physiol. Plant. 2021, 171, 358-370. [CrossRef]

35. Agarie, S.; Uchida, H.; Agata, W.; Kubota, F.; Kaufman, P.B. Effects of silicon on transpiration and leaf conductance in rice plants (Oryza saliva L.). Plant Prod. Sci. 1998, 1, 89-95. [CrossRef]

36. Ahmad, M.; El-Saeid, M.H.; Akram, M.A.; Ahmad, H.R.; Haroon, H.; Hussain, A. Silicon fertilization-A tool to boost up drought tolerance in wheat (Triticum aestivum L.) crop for better yield. J. Plant Nutr. 2016, 39, 1283-1291. [CrossRef]

37. Gong, H.; Chen, K.; Chen, G.; Wang, S.; Zhang, C. Effects of Silicon on Growth of Wheat Under Drought. J. Plant Nutr. 2003, 26, 1055-1063. [CrossRef]

38. Othmani, A.; Ayed, S.; Bezzin, O.; Farooq, M.; Ayed-Slama, O.; Slim-Amara, H.; Ben Younes, M. Effect of Silicon Supply Methods on Durum Wheat (Triticum durum Desf.) Response to Drought Stress. Silicon 2020. [CrossRef]

39. Sattar, A.; Cheema, M.A.; Sher, A.; Ijaz, M.; Ul-Allah, S.; Nawaz, A.; Abbas, T.; Ali, Q. Physiological and biochemical attributes of bread wheat (Triticum aestivum L.) seedlings are influenced by foliar application of silicon and selenium under water deficit. Acta Physiol. Plant. 2019, 41, 146. [CrossRef]

40. Hosseini, S.A.; Maillard, A.; Hajirezaei, M.R.; Ali, N.; Schwarzenberg, A.; Jamois, F.; Yvin, J.-C. Induction of Barley Silicon Transporter HvLsi1 and HvLsi2, increased silicon concentration in the shoot and regulated Starch and ABA Homeostasis under Osmotic stress and Concomitant Potassium Deficiency. Front. Plant Sci. 2017, 8, 1359. [CrossRef]

41. Maillard, A.; Ali, N.; Schwarzenberg, A.; Jamois, F.; Yvin, J.C.; Hosseini, S.A. Silicon transcriptionally regulates sulfur and ABA metabolism and delays leaf senescence in barley under combined sulfur deficiency and osmotic stress. Environ. Exp. Bot. 2018, 155, 394-410. [CrossRef]

42. Massey, F.P.; Massey, K.; Roland Ennos, A.; Hartley, S.E. Impacts of silica-based defences in grasses on the feeding preferences of sheep. Basic Appl. Ecol. 2009, 10, 622-630. [CrossRef]

43. Soininen, E.M.; Bråthen, K.A.; Jusdado, J.G.H.; Reidinger, S.; Hartley, S.E. More than herbivory: Levels of silica-based defences in grasses vary with plant species, genotype and location. Oikos 2013, 122, 30-41. [CrossRef]

44. Ouzounidou, G.; Giannakoula, A.; Ilias, I.; Zamanidis, P. Alleviation of drought and salinity stresses on growth, physiology, biochemistry and quality of two Cucumis sativus L. cultivars by Si application. Rev. Bras. Bot. 2016, 39, 531-539. [CrossRef]

45. Parveen, A.; Liu, W.; Hussain, S.; Asghar, J.; Perveen, S.; Xiong, Y. Silicon priming regulates morpho-physiological growth and oxidative metabolism in maize under drought stress. Plants 2019, 8, 431. [CrossRef] [PubMed]

46. Maghsoudi, K.; Emam, Y.; Ashraf, M.; Pessarakli, M.; Arvin, M.J. Silicon application positively alters pollen grain area, osmoregulation and antioxidant enzyme activities in wheat plants under water deficit conditions. J. Plant Nutr. 2019, 42, $2121-2132$. [CrossRef]

47. Lopes, M.S.; El-Basyoni, I.; Baenziger, P.S.; Singh, S.; Royo, C.; Ozbek, K.; Aktas, H.; Ozer, E.; Ozdemir, F.; Manickavelu, A.; et al. Exploiting genetic diversity from landraces in wheat breeding for adaptation to climate change. J. Exp. Bot. 2015, 66, 3477-3486. [CrossRef]

48. Merah, O.; Deleens, E.; Monneveux, P. Grain yield, carbon isotope discrimination, mineral and silicon content in durum wheat under different precipitation regimes. Physiol. Plant. 1999, 107, 387-394. [CrossRef]

49. Simpson, K.J.; Wade, R.N.; Rees, M.; Osborne, C.P. Still armed after domestication? Impacts of domestication and agronomic selection on silicon defences in cereals. Funct. Ecol. 2017, 31, 2108-2117. [CrossRef]

50. Michel, B.E. Evaluation of the Water Potentials of Solutions of Polyethylene Glycol 8000 Both in the Absence and Presence of Other Solutes. Plant Physiol. 1983, 72, 66-70. [CrossRef]

51. Reidinger, S.; Ramsey, M.H.; Hartley, S.E. Rapid and accurate analyses of silicon and phosphorus in plants using a portable X-ray fluorescence spectrometer. New Phytol. 2012, 195, 699-706. [CrossRef]

52. Johnson, J. Accurate Measurements of Low Z Elements in Sediments and Archaeological Ceramics Using Portable X-ray Fluorescence (PXRF). J. Archaeol. Method Theory 2014, 21, 563-588. [CrossRef]

53. R Core Team. R: A Language and Environment for Statistical Computing; R Foundation for Statistical Computing: Vienna, Austria, 2019. Available online: https:/ /www.R-project.org/ (accessed on 27 April 2018). 
54. Chen, C.T.; Kao, C.H. Osmotic stress and water stress have opposite effects on putrescine and proline production in excised rice leaves. Plant Growth Regul. 1993, 13, 197-202. [CrossRef]

55. Whalley, W.R.; Bengough, A.G.; Dexter, A.R. Water stress induced by PEG decreases the maximum growth pressure of the roots of pea seedlings. J. Exp. Bot. 1998, 49, 1689-1694. [CrossRef]

56. Ma, J.F.; Yamaji, N.; Tamai, K.; Mitani, N. Genotypic Difference in Silicon Uptake and Expression of Silicon Transporter Genes in Rice. Plant Physiol. 2007, 145, 919-924. [CrossRef] [PubMed]

57. Chiba, Y.; Mitani, N.; Yamaji, N.; Ma, J.F. HvLsi1 is a silicon influx transporter in barley. Plant J. 2009, 57, 810-818. [CrossRef] [PubMed]

58. Pei, Z.F.; Ming, D.F.; Liu, D.; Wan, G.L.; Geng, X.X.; Gong, H.J.; Zhou, W.J. Silicon Improves the Tolerance to Water-Deficit Stress Induced by Polyethylene Glycol in Wheat (Triticum aestivum L.) Seedlings. J. Plant Growth Regul. 2010, 29, 106-115. [CrossRef]

59. Xu, L.; Islam, F.; Ali, B.; Pei, Z.; Li, J.; Ghani, M.A.; Zhou, W. Silicon and water-deficit stress differentially modulate physiology and ultrastructure in wheat (Triticum aestivum L.). 3 Biotech 2017, 7, 173. [CrossRef]

60. Ruppenthal, V.; Zoz, T.; Steiner, F.; Do Carmo Lana, M.; Castagnara, D.D. Silicon does not alleviate the adverse effects of drought stress in soybean plants. Semin. Agrar. 2016, 37, 3941-3954. [CrossRef]

61. Hu, J.; Cai, X.; Jeong, B.R. Silicon Affects Root Development, Tissue Mineral Content, and Expression of Silicon Transporter Genes in Poinsettia (Euphorbia pulcherrima Willd.) Cultivars. Plants 2019, 8, 180. [CrossRef]

62. De Camargo, M.S.; Bezerra, B.K.L.; Holanda, L.A.; Oliveira, A.L.; Vitti, A.C.; Silva, M.A. Silicon Fertilization Improves Physiological Responses in Sugarcane Cultivars Grown Under Water Deficit. J. Soil Sci. Plant Nutr. 2019, 19, 81-91. [CrossRef]

63. Gunes, A.; Pilbeam, D.J.; Inal, A.; Coban, S. Influence of silicon on sunflower cultivars under drought stress, I: Growth, antioxidant mechanisms, and lipid peroxidation. Commun. Soil Sci. Plant Anal. 2008, 39, 1885-1903. [CrossRef]

64. Sapre, S.S.; Vakharia, D. Silicon induced physiological and biochemical changes under polyethylene glycol-6000 water deficit stress in wheat seedlings. J. Environ. Biol. 2017, 38, 313-319. [CrossRef]

65. Meunier, J.D.; Barboni, D.; Anwar-ul-Haq, M.; Levard, C.; Chaurand, P.; Vidal, V.; Grauby, O.; Huc, R.; Laffont-Schwob, I.; Rabier, J.; et al. Effect of phytoliths for mitigating water stress in durum wheat. New Phytol. 2017, 215, 229-239. [CrossRef] [PubMed]

66. Ahmad, F.; Aziz, T.; Maqsood, M.A. Effect of silicon application on wheat (Triticum aestivum L.) growth under water deficiency stress. Emir. J. Food Agric. 2007, 19, 1-7. [CrossRef]

67. Grašič, M.; Dobravc, M.; Golob, A.; Vogel-Mikuš, K.; Gaberščik, A. Water shortage reduces silicon uptake in barley leaves. Agric. Water Manag. 2019, 217, 47-56. [CrossRef]

68. Yang, R.; Howe, J.A.; Golden, B.R. Calcium silicate slag reduces drought stress in rice (Oryza sativa L.). J. Agron. Crop Sci. 2019, 205, 353-361. [CrossRef]

69. Chen, W.; Yao, X.; Cai, K.; Chen, J. Silicon alleviates drought stress of rice plants by improving plant water status, photosynthesis and mineral nutrient absorption. Biol. Trace Elem. Res. 2011, 142, 67-76. [CrossRef] [PubMed] 